\title{
First Report of Spirocerca Lupi Larva in Dung Beetles (Scarabaeus Armeniacus) in Iran: A Morphological and Molecular Identification
}

\section{Sina Mohtasebi}

TUMS: Tehran University of Medical Sciences

\section{Aref Teimouri}

Shiraz Medical School: Shiraz University of Medical Sciences

\section{Mohammad Javad Abbaszadeh Afshar}

TUMS: Tehran University of Medical Sciences

\section{Iraj Mobedi}

TUMS: Tehran University of Medical Sciences

\section{Hamed Abbasian}

TUMS: Tehran University of Medical Sciences

\section{Niloofar Totonchian}

Tehran University: University of Tehran

\section{Alireza Mohtasebi \\ Shahid Beheshti University \\ Mahya Allahmoradi}

TUMS: Tehran University of Medical Sciences

Gholamreza Mowlavi ( $\nabla$ molavig@yahoo.com )

Tehran University of Medical Sciences

\section{Research article}

Keywords: Dung beetles, Scarabaeus armeniacus, Spirocerca lupi, cox1, Iran

Posted Date: October 22nd, 2020

DOI: https://doi.org/10.21203/rs.3.rs-94558/v1

License: (c) (1) This work is licensed under a Creative Commons Attribution 4.0 International License. Read Full License 


\section{Abstract}

Background: Dung beetles are detritivores insects. They naturally use feces of vertebrates as foods and reproduction beds. This leads to frequent contacts between dung beetles and parasitic helminths. The current study was carried out to assess infections of dung beetles with larval stages of helminths in rural areas of Taleqan County, Alborz Province, Iran. In total, 200 dung beetles were randomly collected in June 2017 from the highlands of Taleqan County. Beetles were dissected in normal saline and carefully studied using stereomicroscopy. Morphological characteristics of the recovered larvae were drawn using camera lucida equipped microscope at 400x magnification. Furthermore, genomic DNAs of the recovered larvae were extracted and PCR amplifications of the mitochondrial cytochrome $c$ oxidase subunit 1 (cox1) genes were carried out and the amplicons were sequenced.

Results: All collected dung beetles were identified as Scarabaeus armeniacus from Scarabaeidae family (55.5\% were male and $44.5 \%$ female). Three females of the beetles were infected with nematode larva, morphologically identified as the third-stage of Spirocerca lupi larvae. The average length and width of the larvae were $2.95(2.81-3.15 ; \mathrm{Cl} 95 \%)$ and $0.12(0.1-0.15 ; \mathrm{Cl} 95 \%) \mathrm{mm}$, respectively. The phylogenetic analysis showed that $S$. lupi belonged to a clade within Spirocercidae family, well separated from Onchocercidae family.

Conclusions: In the current study, S. armeniacus was introduced as a potentially biological vector for the transmission of $S$. lupi to vertebrates in the region. To the best of the authors' knowledge, this is the first reported on larval stages of $S$. Iupi in $S$. armeniacus.

\section{Background}

Dung beetles are diverse detritivores insects, which use feces of vertebrates for feed and reproduction from Cenozoic Era [1]. Several coprophagous species in Scarabaeidae (Scarabaeinae and Aphodiinae subfamilies) and Geotrupidae (Geotrupinae subfamily) families play significant roles in transmission of vertebrate parasites. These arthropods have intense contacts with animal and human feces, constant accessing to helminth eggs [2]. Therefore, dung beetles play important roles as intermediate hosts for helminths, including Gongylonema sp., Acanthocephalans and Sprirocerca [3-5]. Spirocercosis is a canine disease caused by Spirocerca lupi (S. Iupi) and Spirocerca vulpis (S. vulpis) nematodes which potentially results in fatalities in domestic dogs (Carnivora: Canidae). The $S$. lupi is a cosmopolitan parasite, more commonly found in warmer tropical and subtropical regions of the world [6-8]. A majority of reports are from Brazil, the southern United States, Kenya, India, Israel and South Africa [9-14]. Usually, the worms are coiled in a spiral pink form, with males are up to 54 and females up to $80 \mathrm{~mm}$ in length [6, 7]. This nematode includes an indirect lifecycle, and various species of coprophagous dung beetles (Coleoptera: Scarabaeidae) serve as intermediate hosts after ingesting embryonated eggs of S. lupi through feces of canids. Infection transmissions to humans and animals are similar in principles, which can be resulted from the ingestion of infected arthropods by humans or grazing in grasslands by 
animals. However, a wide variety of paratenic hosts, including mammals, birds and reptiles, are known [6, 7].

Recently, studies have shown that mitochondrial DNA (mtDNA) regions are useful in analysis of population genetics, biology, epidemiology and diagnosis of parasitic nematodes of human and veterinary significances $[15,16]$. Significant variations in the nematode mitochondrial genome are reported, compared to other animal species [17]. In fact, DNA sequencing of informative regions within the mtDNA gene encoding cytochrome c oxidase subunit 1 (cox 1 ) has led to basic and applied potential studies of Spirurida nematodes [18-21]. In studies on sequence variability and population genetics of parasitic nematodes and arthropods and their diagnostic approaches, the cox 1 gene has been described as an appropriate choice $[15-17,22,23]$. Hence, cox 1 was considered for the molecular identification of this parasite and its molecular characterization in the current study. Rich literatures of clinical, diagnostic

and epidemiological elements of dog spirocercosis are available. To date, a few studies have been carried out on the host-parasite interactions of dung beetles and S. Iupi [24-26]. Therefore, the current study was carried out for the first time to assess infections of dung beetles with larval stages of helminths in rural areas of Taleqan County, Alborz Province, Iran, using morphological and molecular analyses. Molecular characteristics were characterized by sequencing of the $\operatorname{cox} 1$ gene to detail larval stages of S. lupi in Scarabaeus armeniacus (S. armeniacus) and assess its taxonomic position within the genus.

\section{Results}

\section{Species identification of the dung beetles}

Of the dung beetles, $55.5 \%(111 / 200)$ were males and $44.5 \%(89 / 200)$ females, identified as $S$. armeniacus from Scarabaeidae family using available entomology keys. The posterior margin of metafemore in this species was marginate. Pronotum was characterized using sparse distributed fine puncture with usual sizes of 11-25 mm (Fig. 1).

\section{Morphological Findings Of The Recovered Larvae}

Larvae were recovered from three female $S$. armeniacus beetles, based on the published description of infective third-stage (L3) larvae of S. lupi. One of the beetles included one S. lupi larva while the other two beetles included three and six S. Iupi larvae. Identification of the L3 larvae of S. lupi was completed by referring to characteristics described in keys. The average length and width of the larvae were 2.95 (2.81$3.15 \mathrm{~mm} ; \mathrm{Cl}: 95 \%)$ and $0.12 \mathrm{~mm}(0.1-0.15 \mathrm{~mm}$; Cl: $95 \%)$, respectively. The other measurements included distance of nerve ring [0.111 $\mathrm{mm}(0.108-0.113 \mathrm{~mm}), \mathrm{Cl}: 95 \%]$ and excretory pore from the anterior end [0.09 mm (0.07-0.11 mm, Cl: $95 \%]$, respectively. The average size of buccal capsule was $0.051 \times$ $0.013 \mathrm{~mm}$. the average size of rectum and tail were 0.053 and $0.041 \mathrm{~mm}$, respectively. Most of the larvae moved freely in the normal saline after the beetle dissection; some of them were still in encysted form, which were spontaneously emerged. Although some cysts were found attached to the tracheal tubes, 
most of them were free in the normal saline. In morphological characteristics of $S$. lupi larvae, thickness of the larvae was uniform, with transverse ridges. Two cephalic horns were recognized at the interior end of the terminal mouth, leading to a strong, sclerotic cylindrical buccal capsule. The tail was formed with five closely sets of circular spines. Camera lucida drawings of the anterior and posterior ends of $S$. lupi 3rd larval stage are illustrated in Fig. 2.

\section{Molecular Findings Of The Recovered Larvae}

Specimens of $S$. Iupi were successfully amplified with nearly 680-bp amplicons for the partial cox1 genes. In this study, a unique nucleotide sequence of the partial cox1 gene from S. lupi was annotated in GenBank database (accession number MT522373). Phylogenetic analysis based on the cox1 gene illustrated that $S$. lupi belonged to a clade within the Spirocercidae family and was well separated from Onchocercidae family (Fig. 3). In this study, the sequence alignment revealed high levels of sequence homologies between S. lupi isolates and those globally documented in GenBank (Fig. 4). Results showed that the current nucleotide sequence of $S$. Iupi included $100 \%$ identity with the recovered isolates of dogs from South Africa (EF394612.1), Israel (EF394606.1), Austria (EF394605.1) and Iran (EF394608.1) (Fig. 4). Moreover, pairwise distance showed intraspecies genetic variations of $0-0.4 \%$ between the current isolate of S. lupi, and those available in GenBank.

\section{Discussion}

Regarding prospective roles of dung beetles in transmission of certain helminths such as acanthocephalans and Spirurid nematodes to humans and animals, faunistic investigation of their parasites seems to include great veterinary and medical significances [1]. The current study firstly demonstrated roles of dung beetles (S. armeniacus), as intermediate hosts of $S$. Iupi, in Iran. Literatures are available on spirocercosis prevalence in dogs in Iran. Oryan et al. reported $19 \%$ of $S$. lupi infection in stray dogs in the southern regions of Iran [26]. In Mirzayans et al. study, S. lupi was reported as one of the most common helminths in house-dogs in Tehran Province, Iran [27]. Moshfe et al. documented $17.4 \%$ of $S$. Iupi in stray dogs in western areas of Iran [28]. In Sadighian study, $45.4 \%$ of the stray dogs were infected by S. Iupi in Northern Iran [29]. Moreover, S. Iupi infection in Vulpes vulpes (red fox) in Northwestern Iran was reported as $17.9 \%$ [30]. In some of these studies, high prevalence of spirocercosis is attributed to the presence of dung beetles. However, presence of intermediate hosts (e.g. amphibians, reptiles, lizards, domestic and wild birds) and small mammals (e.g. mice and rabbits) as well as different life and hunting styles are important factors in prevalence of $S$. Iupi in carnivores [26, 31, 32].

To the best of the authors' knowledge, no studies have been carried out on S. lupi infection in dung beetles in Iran. However, dung beetle infection with Gongylonema spp. has been recorded in Northwestern Iran [33]. Studies have documented presence of $S$. armeniacus in Central and Northern Iran [34, 35]. Dung beetles play critical roles in ecosystem, manure and nutrient recycling. They rely on feces for food for themselves and their larvae and lay their eggs in feces. An individual dung beetle can bury feces 250 
times larger than that a beetle can in one night. Dung beetles are capable of carrying weights, nearly 50 times heavier than their body weights. Many dung beetles prefer a certain type of animal feces and can fly up to 10 miles to find their desirable food [36, 37]. Several factors affect dung beetle communities, including nature of the soil substrate, flora of the specific region, rainfall and temperature [7, 23]. In Iran, various aspects of $S$. lupilife cycle is still undescribed. In the present study, beetles were collected in summer. Prevalence of spirocercosis differs over a comparatively brief period [7, 38]. In a study by Chhabra and Singh [24], prevalence of infection in beetles increased in mid-season of laboratory-infected dung beetles. In another study, detection rates of spirocercosis during cold months have significantly been higher [39]. This might be explained by the seasonality in the studied country.

Nucleotide BLAST analysis from the current study showed high sequence homologies between S. Iupi isolates and those from other studies. The current results showed that nucleotide sequence of $S$. Iupi from this study included 100\% identity with recovered isolates of dogs from South Africa (EF394612.1), Israel (EF394606.1), Austria (EF394605.1) and Iran (EF394608.1) [40]. Based on the pairwise distance of the isolate from the current study, intraspecies genetic variation within $S$. lupi nucleotide sequences included $0-0.4 \%$ with an overall average of $0.1 \%$ between the current isolate of $S$. lupi and the sequences available in GenBank. Several studies have been carried out on the molecular characterization of Spirocerca spp. In Traversa et al. study, the cox 1 gene of $S$. lupi collected from five countries was investigated and only a low genetic variation within the sequences was detected, demonstrating at least 99\% nucleotide similarity [40]. In contrast, de Waal et al. reported significant genetic diversities in Spirocerca isolates collected from a dog [41]. A study by Rojas et al. on detection of spirocercosis in dogs using HRM qPCR in fecal samples showed that HRM qPCR of ITS1 included the best performance in limit of detection and absence of cross-amplification with other canine parasites [42]. Ruggeri et al. detected $18 S$ ribosomal DNA (rDNA) of $S$. lupi gene in cerebrospinal fluid (CSF) of presumptively-affected dogs using PCR. Results revealed that PCR targeting 18 S rDNA of S. Iupi in CSF was capable of antemortem diagnosis of canine intraspinal spirocercosis [43].

\section{Conclusion}

In the current study, S. armeniacus has been introduced as a potentially biological vector for the transmission of $S$. lupi to vertebrates in Iran. To the best of the authors' knowledge, this is the first report on the larval stages of $S$. Iupi in S. armeniacus. Further studies are necessary to investigate better control and prevention of the disease in dogs. Better knowledges of dynamics of the intermediate host-parasite intersections between dung beetles and $S$. Iupi in Iran can establish preventive methods to limit spread of this disease in domestic dogs.

\section{Materials And Methods}

\section{Sample collection}


Totally, 200 dung beetles were randomly collected in June 2017 from the highlands of Taleqan County, Alborz Province, Iran $\left(36.1748^{\circ} \mathrm{N}, 50.7650^{\circ} \mathrm{E}\right)$, a common passage of jackals, foxes and other canids and felids (Fig. 5) [44]. Wild boar, dog and livestock dung pitfall traps were used to capture dung beetles, previously described by Du Toit et al. [14]. Trapped dung beetles were transferred to the Helminthology Lab of the Department of Medical Parasitology and Mycology, Tehran University of Medical Sciences, Tehran, Iran, using ventilated containers.

\section{Species identification of the dung beetles}

At the time of the assessment, most of the dung beetles were still alive. Therefore, dung beetles were stored in a refrigerator with autoclaved soil for $2 \mathrm{~h}$ to immobilize them. Then, species and sexes of the collected beetles were identified taxonomically, using entomology keys [45].

\section{Morphological analysis of the recovered larvae}

Beetles were dissected in normal saline solution and carefully studied for the presence of parasites with special focuses on larval stages using stereomicroscope. The beetles have been reported individually as positive or negative for larval stages of helminths. For positive beetles, larvae were removed and transferred into normal saline on ice for $1 \mathrm{~h}$ to relax and immobilize [33]. Removed larvae were transferred into lactophenol and $70 \%$ ethanol for morphological and molecular studies. Morphological characteristics of the isolates were recorded carefully using camera lucida equipped microscope at $400 \times$ magnification. Identification was comparatively carried out based on taxonomic key references [46].

\section{Molecular analysis of the recovered larvae}

\section{DNA extraction}

Ethanol preserved larvae were washed three times with sterile distilled water by centrifugation at $5000 \times \mathrm{g}$ for $5 \mathrm{~min}$ to remove ethanol. Then, larvae were subjected to five cycles of freezing in liquid nitrogen and thawing in boiling water. Approximately $300 \mathrm{mg}$ of glass beads ( $0.5 \mathrm{~mm}$ in diameter) were added to the larvae and shaken intensively for 5 min. Then, genomic DNA was extracted using genomic DNA extraction kit (GeneAll Exgene, South Korea) according to the manufacturer's instructions and stored at $-20^{\circ} \mathrm{C}$ until use. The DNA concentration was assessed spectrometrically (NanoDrop ND-1000, Thermo Fischer Scientific, USA) at $260 \mathrm{~nm}$. The $260 / 280$ absorbance ratios of the DNA samples included 1.8-2.0, indicating no major protein contaminations.

\section{Amplification of the cox1 gene and sequencing of the amplicons}

Polymerase chain reaction (PCR) on cox1 gene was carried out using primer set of NTF ( $5^{\prime}$ TGATTGGTGGTTTTGGTAA-3') and NTR (5'-ATAAGTACGAGTATCAATATC-3') as previously described for Spirurida [40]. The PCR amplification was carried out in a final reaction mixture of $50 \mu \mathrm{L}$, including $25 \mu \mathrm{L}$ of $2 x$ red PCR master mix (Ampliqon, Denmark), $2 \mu \mathrm{L}$ of each primer $(10 \mathrm{pmol}), 5 \mu \mathrm{L}$ of the extracted DNA and $16 \mu \mathrm{l}$ of sterile distilled water. A negative control (distilled water) and positive control (extracted DNA 
from S. lupi provided by the Faculty of Veterinary Medicine, University of Tehran) were used in each set. Amplification was carried out using PeqSTAR Thermal Cycler (PeqLab, Germany) using the following cycling protocol of initial denaturation at $94^{\circ} \mathrm{C}$ for $7 \mathrm{~min}$, followed by 40 cycles of denaturation at $94{ }^{\circ} \mathrm{C}$ for $1 \mathrm{~min}$, annealing at $58^{\circ} \mathrm{C}$ for $1 \mathrm{~min}$ and extension at $72{ }^{\circ} \mathrm{C}$ for $1 \mathrm{~min}$. Final extension was carried out at $72{ }^{\circ} \mathrm{C}$ for $10 \mathrm{~min}$. Amplified products were electrophoresed on $1.5 \%$ agarose gels and visualized using UV transilluminator. The PCR products were sequenced using Sanger method in both directions (Bioneer, South Korea).

\section{Sequence analysis}

Sequences were edited and trimmed using Chromas software v.2.6.1 (Chromas, Australia). Analysis of the sequencing data was carried out using BLAST program and NCBI databases (http://www.ncbi.nlm.nih.gov/). Multiple sequence alignments were carried out using Clustal W method and BioEdit software v.7.1 (http://www.mbio.ncsu.edu/bioedit/bioedit.html) and results were compared to sequence results from GenBank database.

\section{Phylogenetic analysis}

Sequences were edited and compared to entries from NCBI GenBank for further analysis. The best-fit model of nucleotide substitution was statistically selected by the MEGA software v.6.0 (Pennsylvania State University, USA) [47]. The phylogenetic tree of Spirocerca spp. was constructed using the Maximum Likelihood (ML) method in agreement with Hasegawa-Kishino-Yano model with uniform rates for transitions and transversions. Bootstraps of 1,000 replicates were used for the assessment of topology reliability of the trees.

\section{Abbreviations}

L3: third stage of larvae; cox1: cytochrome c oxidase subunit 1; mtDNA: mitochondrial DNA; PCR:

Polymerase chain reactions; BLAST: basic local alignment search tool; ML method: Maximum Likelihood method; HRM: High Resolution Melting Analysis; qPCR: quantitative PCR; rDNA: ribosomal DNA; CSF: cerebrospinal fluid.

\section{Declarations}

Ethics approval and consent to participate

Not applicable.

\section{Consent for publication}

Not applicable.

\section{Availability of data and materials}


All data generated or analyzed during this study are included in this published article. The original datasets are available upon request to the corresponding author. The generated sequence of S. Iupicox 1 gene was deposited in the GenBank database under the accession number MT522373.

\section{Competing Interests}

The authors declare that they have no competing interests.

\section{Funding}

This study did not receive any specific grants from funding agencies in the public, commercial or not-forprofit sectors.

\section{Authors' contributions}

SM and GM conceived and designed the study. AM and MA collected the dung beetles. NT performed the entomological identification. HA dissected and examined the collected dung beetles. IM performed the morphological identification of the recovered larvae. SM, AT and MJAA drafting the manuscript and performed all DNA extraction, PCR and phylogenetic analyses. All authors read and approved the final manuscript.

\section{Acknowledgements}

The authors are grateful to Tehran University of Medical Sciences for cooperation during the study.

\section{Authors' information}

${ }^{1}$ Department of Medical Parasitology and Mycology, School of Public Health, Tehran University of Medical Sciences, Tehran, Iran. ${ }^{2}$ Department of Parasitology and Mycology, School of Medicine, Shiraz University of Medical Sciences, Shiraz, Iran. ${ }^{3}$ Department of Medical Parasitology and Mycology, School of Medicine, Jiroft University of Medical Sciences, Jiroft, Iran. ${ }^{4}$ School of Biology, College of Science, University of Tehran, Tehran, Iran. ${ }^{5}$ Department of Environmental Health, Shahid Beheshti University of Medical Sciences, Tehran, Iran.

\section{References}

1. Nichols E, Gomez A. Dung beetles and fecal helminth transmission: patterns, mechanisms and questions. Parasitology. 2014;141(5):614-23.

2. Miller A. Dung beetles (Coleoptera, Scarabaeidae) and other insects in relation to human feces in a hookworm area of southern Georgia. The American Journal of Tropical Medicine Hygiene. 1954;3(2):372-89.

3. Eberhard ML, Busillo C. Human Gongylonema infection in a resident of New York City. The American Journal of Tropical Medicine Hygiene. 1999;61(1):51-2. 
4. Molavi G, Massoud J, Gutierrez Y. Human gongylonema infection in Iran. J Helminthol. 2006;80(4):425-8.

5. Mowlavi G, Mikaeili E, Mobedi I, Kia E, Masoomi L, Vatandoost H. Scarab beetle (Coleoptera: Scarabaeidae) fauna in Ardabil province, north west Iran. Journal of Arthropod-Borne Diseases. 2008;2(2):35-41.

6. Anderson R. The superfamily Spiruroidea: $\mathrm{CABi} ; 2000$.

7. Bailey WS. Spirocerca lupi: a continuing inquiry. J Parasitol. 1972;58(1):3-22.

8. van der Merwe LL, Kirberger RM, Clift S, Williams M, Keller N, Naidoo V. Spirocerca lupi infection in the dog: a review. Vet J. 2008;176(3):294-309.

9. Oliveira-Sequeira T, Amarante A, Ferrari T, Nunes L. Prevalence of intestinal parasites in dogs from São Paulo State, Brazil. Vet Parasitol. 2002;103(1-2):19-27.

10. Dixon K, McCue J. Further observations on the epidemiology of Spirocerca lupi in the southeastern United States. J Parasitol. 1967;53(5):1074-5.

11. Brodey R, Thomson R, Sayer P, Eugster B. Spiroceca lupi infection in dogs in Kenya. Vet Parasitol. 1977;3(1):49-59.

12. Ramachandran P, Shakir S, Ramakrishnan R. Spirocercosis in canines-a necropsy survey. Journal of Veterinary Science Animal Husbandry. 1984;13(3):132-5.

13. Lobetti R. Survey of the incidence, diagnosis, clinical manifestations and treatment of Spirocerca lupi in South Africa: research communication. J S Afr Vet Assoc. 2000;71(1):43-6.

14. Du Toit C, Scholtz $\mathrm{CH}$, Hyman W. Prevalence of the dog nematode Spirocerca lupi in populations of its intermediate dung beetle host in the Tshwane (Pretoria) Metropole, South Africa. Onderstepoort J Vet Res. 2008;75(4):315-21.

15. Hu M, Chilton NB, Gasser RB. The mitochondrial genomics of parasitic nematodes of socioeconomic importance: recent progress, and implications for population genetics and systematics. Adv Parasitol. 2004;56:134-213.

16. Hu M, Gasser RB. Mitochondrial genomes of parasitic nematodes-progress and perspectives. Trends in Parasitology. 2006;22(2):78-84.

17. Blouin MS, Yowell CA, Courtney $\mathrm{CH}$, Dame JB. Host movement and the genetic structure of populations of parasitic nematodes. Genetics. 1995;141(3):1007-14.

18. Casiraghi M, Anderson T, Bandi C, Bazzocchi C, Genchi C. A phylogenetic analysis of filarial nematodes: comparison with the phylogeny of Wolbachia endosymbionts. Parasitology. 2001;122(1):93-103.

19. Ngarmamonpirat C, Waikagul J, Petmitr S, Dekumyoy P, Rojekittikhun W, Anantapruti MT. Analysis of sequence variation in Gnathostoma spinigerum mitochondrial DNA by single-strand conformation polymorphism analysis and DNA sequence. Parasitol Int. 2005;54(1):65-8.

20. Otranto D, Testini G, De Luca F, Hu M, Shamsi S, Gasser R. Analysis of genetic variability within Thelazia callipaeda (Nematoda: Thelazioidea) from Europe and Asia by sequencing and mutation 
scanning of the mitochondrial cytochrome c oxidase subunit 1 gene. Mol Cell Probes. 2005;19(5):306-13.

21. Ando K, Tsunemori M, Akahane H, Tesana S, Hasegawa $H$, Chinzei Y. Comparative study on DNA sequences of ribosomal DNA and cytochrome $c$ oxidase subunit 1 of mitochondrial DNA among five species of gnathostomes. J Helminthol. 2006;80(1):7-13.

22. Shao R, Barker S. Mitochondrial genomes of parasitic arthropods: implications for studies of population genetics and evolution. Parasitology. 2007;134(2):153-67.

23. Traversa D, Otranto D. A new approach for the diagnosis of myiasis of animals: the example of horse nasal myiasis. Veterinary parasitology. 2006;141(1-2):186-90.

24. Chhabra B, Singh K. study of the life-history of Spirocerca lupi: intermediate hosts and their biology. Indian Journal of Animal Sciences. 1973;43:49-54.

25. Chhabra R, Singh K. The life-history of Spirocerca lupi: Development and biology of infective juvenile [India]. Indian Journal of Animal Sciences. 1977;47(4):178-84.

26. Oryan A, Sadjjadi S, Mehrabani D, Kargar M. Spirocercosis and its complications in stray dogs in Shiraz, southern Iran. Veterinary Medicine - Czech. 2008;53(11):617-24.

27. Mirzayans A, Eslami A, Anwar M, Sanjar M. Gastrointestinal parasites of dogs in Iran. Trop Anim Health Prod. 1972;4(1):58-60.

28. Moshfe A, Mowlavi G, Mobedi I, Cheraghzade R, Askarian S, Mohammadi R, Nouripour S, Zahabioun F, Imani P, Mirsepahi N. Fauna of Zoontic Parasites of Stray Dogs in Yasouj Suburbs in 2008. Armaghane Danesh. 2011;16(1):80-9.

29. Sadighian A. Helminth parasites of stray dogs and jackals in Shahsavar area, Caspian region, Iran. The Journal of Parasitology. 1969;55(2):372-4.

30. Khanmohammadi M, Fallah E, Reyhani-Rad S. Epidemiological studies on fauna and prevalence of parasite helminthes on red fox (Vulpes vulpes) in Sarab district, East Azerbaijan province, Iran. Ann Biol Res. 2011;2(5):246-51.

31. Anderson RC. Nematode parasites of vertebrates: their development and transmission: CABi; 2000.

32. Soulsby E. Helminths, arthropods and protozoa of domesticated animals. The ELBS and Baillier Tindall. London: UK; 1986.

33. Mowlavi G, Mikaeili E, Mobedi I, Kia E, Masoomi L, Vatandoost H. A survey of dung beetles infected with larval nematodes with particular note on copris lunaris beetles as a vector for Gongylonema sp. in Iran. The Korean Journal of Parasitology. 2009;47(1):13.

34. Makhan D, Saeizad FM, Hawkeswood TJ. Some new records of dung beetles (Coleoptera: Scarabaeidae) from Namakeh village in Damghan County, Semnan Province, Iran. Calodema. 2017;587:1-4.

35. Gharakhloo MM, Ziani S. Occurrence of scarab beetles inside rodent burrows in some parts of Iran (Coleoptera: Scarabaeidae). Zoology in the Middle east. 2009;46(1):95-8. 
36. Thomas ML. Dung beetle benefits in the pasture ecosystem. Zu finden in http://attra ncat org/attrapub/PDF/dungbeetle pdf [Zitiert am 2504 2007] 2001.

37. Emlen DJ. The evolution of animal weapons. Annu Rev Ecol Evol Syst. 2008;39:387-413.

38. Gottlieb Y, Markovics A, Klement E, Naor S, Samish M, Aroch I, Lavy E. Characterization of Onthophagus sellatus as the major intermediate host of the dog esophageal worm Spirocerca lupi in Israel. Vet Parasitol. 2011;180(3-4):378-82.

39. Mazaki-Tovi M, Baneth G, Aroch I, Harrus S, Kass PH, Ben-Ari T, Zur G, Aizenberg I, Bark H, Lavy E. Canine spirocercosis: clinical, diagnostic, pathologic, and epidemiologic characteristics. Vet Parasitol. 2002;107(3):235-50.

40. Traversa D, Costanzo F, lorio R, Aroch I, Lavy E. Mitochondrial cytochrome c oxidase subunit 1 (cox1) gene sequence of Spirocerca lupi (Nematoda, Spirurida): avenues for potential implications. Veterinary parasitology. 2007;146(3-4):263-70.

41. de Waal PJ, Gous A, Clift SJ, Greeff JM. High within-host genetic variation of the nematode Spirocerca lupi in a high-density urban dog population. Vet Parasitol. 2012;187(1-2):259-66.

42. Rojas A, Segev G, Markovics A, Aroch I, Baneth G. Detection and quantification of Spirocerca lupi by HRM qPCR in fecal samples from dogs with spirocercosis. Parasites Vectors. 2017;10(1):435.

43. Ruggeri M, Rojas A, Chai O, Purzyc H, Hanael E, Rapoport K, Barnoon I, Konstantin L, Baneth G, Shamir M. Detection of intraspinal Spirocerca lupi in canine cerebrospinal fluid by polymerase chain reaction. J Comp Pathol. 2019;170:105-12.

44. Mohtasebi S, Tabatabaei F. Evidence of the Presence of Lutra lutra in Taleqan, Alborz Province, Iran. IUCN Otter Spec Group Bull. 2018;35(3):156-8.

45. Zídek J, Pokorný S. Illustrated keys to Palearctic Scarabaeus Linné (Scarabaeidae). Animma X. 2008;27:1-28.

46. Sen K, Anantaraman M. Some observations on the development of Spirocerca lupi in its intermediate and definitive hosts. J Helminthol. 1971;45(2-3):123-32.

47. Tamura K, Stecher G, Peterson D, Filipski A, Kumar S: MEGA6: molecular evolutionary genetics analysis version 6.0. Molecular Biology and Evolution 2013, 30(12):2725-2729.

\section{Figures}



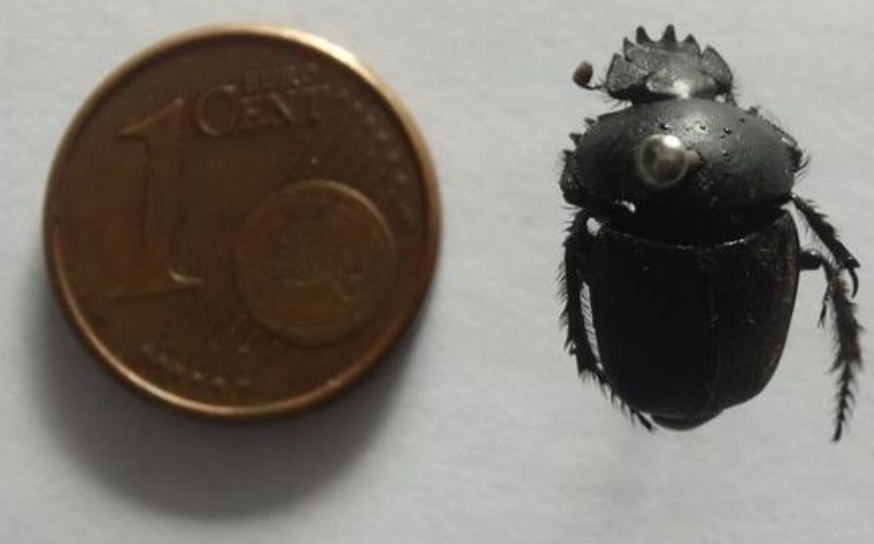

a

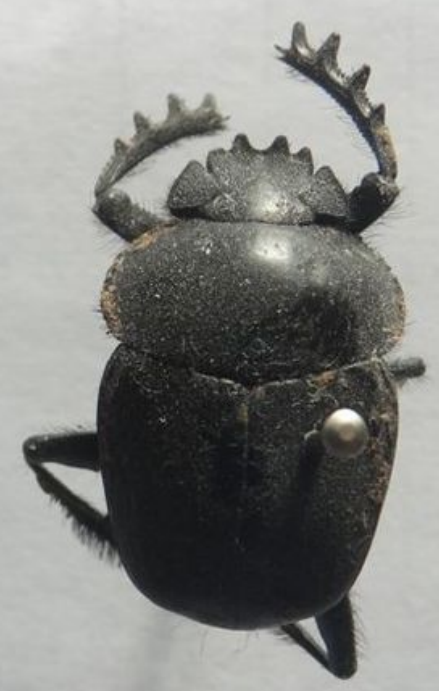

(b)

Figure 1

Scarabaeus armeniacus from family scarabidae. (a) Male (b) Female 

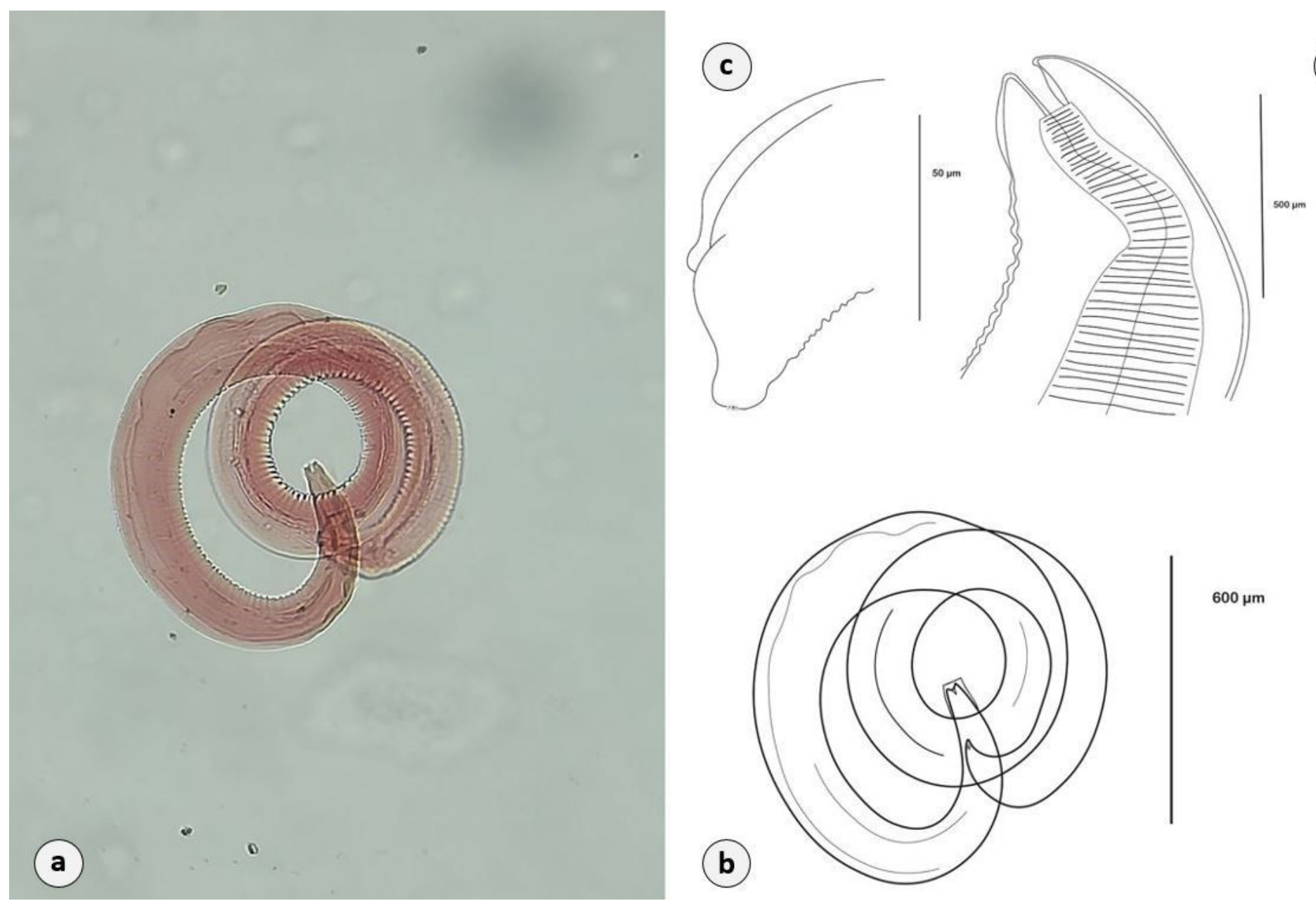

(d)

\section{Figure 2}

3rd Larval stage of Sprirocerca lupi recovered from the Scarabaeus armeniacus beetles (a), Camera lucida drawings of the larval stage (b), and its anterior (c) and posterior (d) ends. 


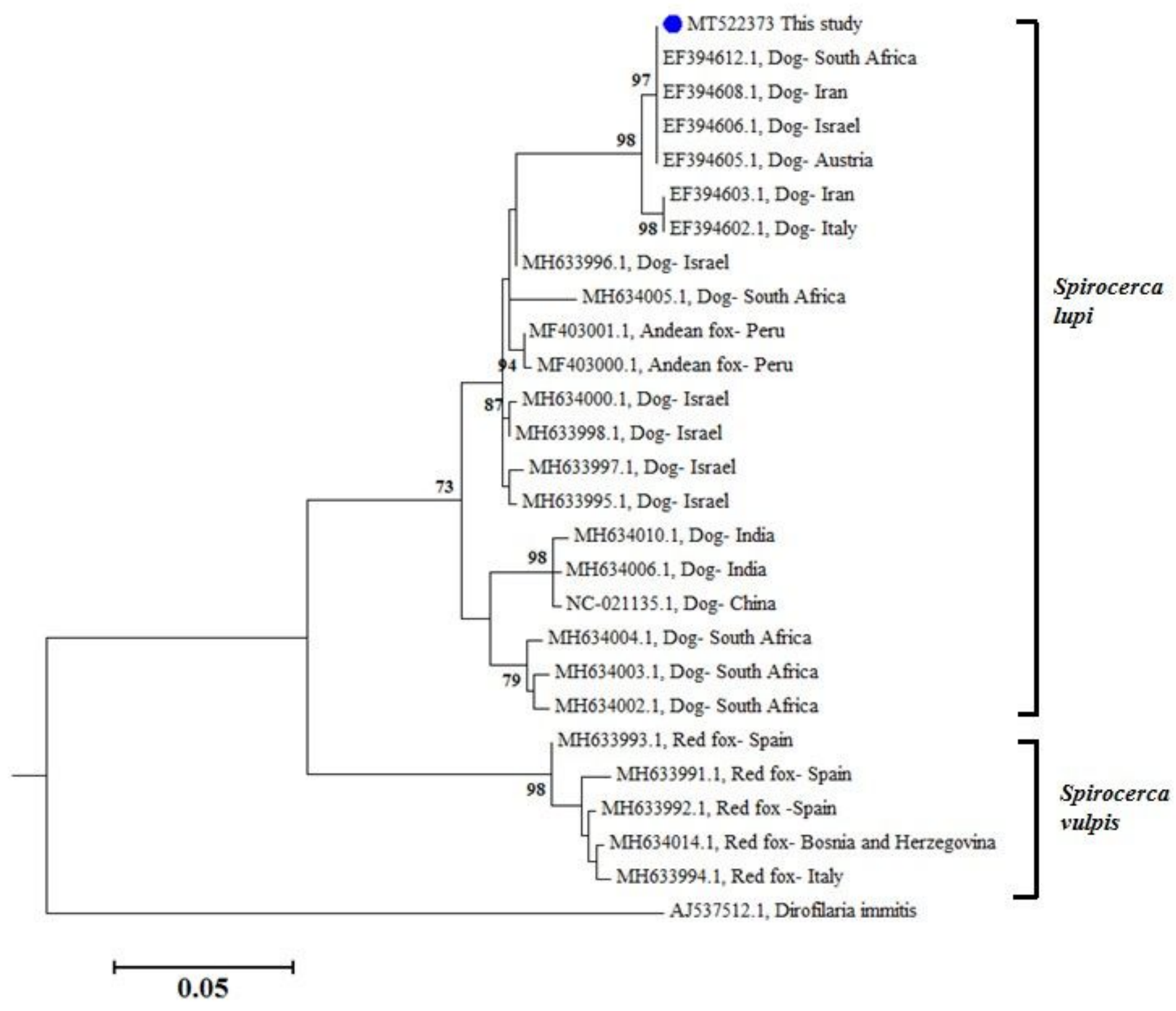

\section{Figure 3}

Phylogenetic tree obtained via the Maximum Likelihood (ML) method and Hasegawa-Kishino-Yano model based on the cox 1 gene (The blue circle indicates the sequence derived from this study). The numbers above branches correspond to bootstrap values based on 1,000 replicates. Branches without numbers include values of less than $70 \%$. Dirofilaria immitis served as an outgroup. Scale bar represented 0.05 changes per nucleotide 


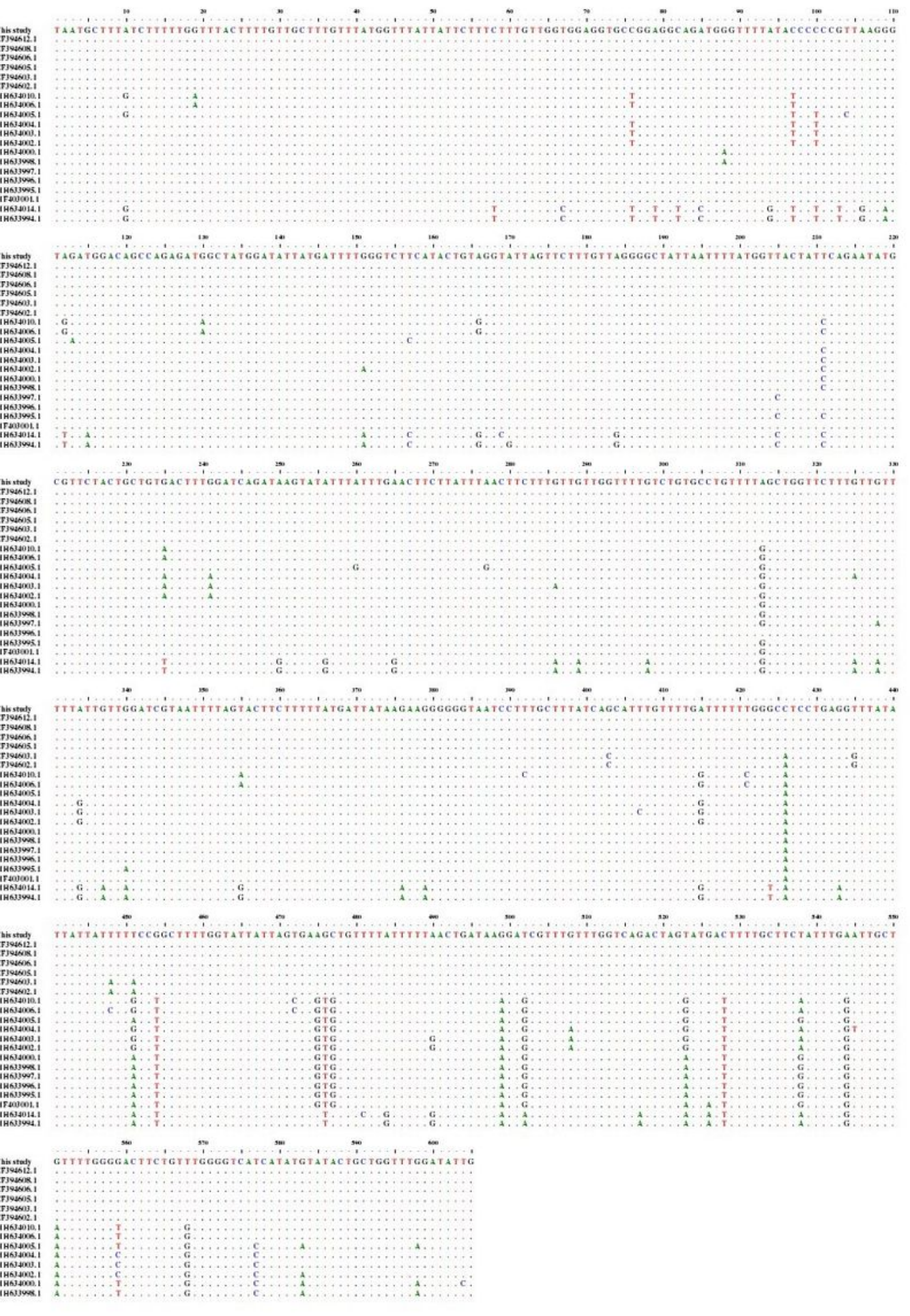

\section{Figure 4}

Sequence alignment of Spirocerca spp. isolate obtained in the current study based on cox 1 gene by Clustal W method via Bioedit software version 7.1 


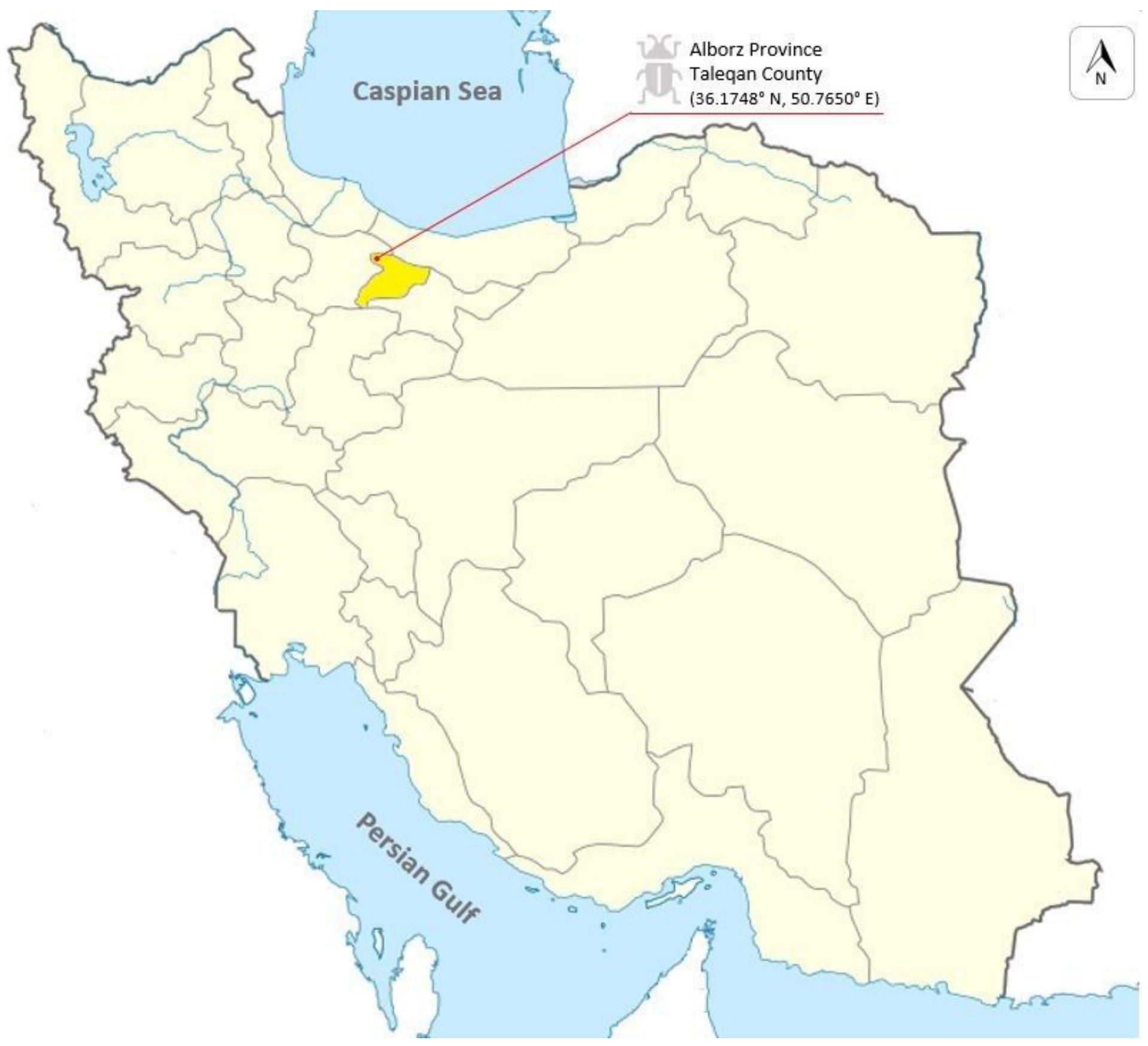

\section{Figure 5}

Map of Iran, Taleqan County in Alborz Province Note: The designations employed and the presentation of the material on this map do not imply the expression of any opinion whatsoever on the part of Research Square concerning the legal status of any country, territory, city or area or of its authorities, or concerning the delimitation of its frontiers or boundaries. This map has been provided by the authors. 